\title{
Planning Risk Assessment of Extension Smart Grid Model based on Multi Layer Model
}

\author{
Xiaoyan $\mathrm{LI}^{1}$, Chenxi WU², Dangye ${ }^{1}$, Xuejing ${ }^{1}$ \\ ${ }^{1}$ Xi'an Electric Power College, Xi'an, China \\ ${ }^{2}$ College of automation, Hangzhou Dianzi University, Hangzhou, China
}

Keywords: Multilayer Model, Scalable, Grid Model, Planning Risk, Evaluation System.

\begin{abstract}
Smart grid technology is developing globally. Countries all over the world are making investment to change the traditional smart grid. They have started to readjust their organizations to support smart grid. At the preliminary stage, some software models have been adopted to quantify evaluation to monitor smart grid in realization and schedule. At present, some smart grid interoperability maturity models, investment models of smart grid, smart grid maturity models and smart grid concept models are very useful. To measure the communication of current automation and other fields, allocation and demand resources adopt smart grid interoperability maturity model. With their strategies, the investment model of smart grid is applied to calculate the investments of different smart grids. Smart grid maturity model is used for the hydropower planning transformation in smart grid; prioritize the progress of task and measurement in each stage. The concept model of smart grid is applied to analyze the development of different standards and interoperability smart grid. The proposal of a new smart grid monitoring model is helpful to understand the smart grid deployment and the ability in electrical utilities.
\end{abstract}

\section{Introduction}

Power grid provides power to consumers (individuals and industries). This process mainly takes place in two systems, including transmission system (TS) and distribution system (DS). TS transmission delivers power from power plant to distribution substation and delivers power from distribution substation to the end consumers. Traditionally, grid interconnected transmission system refers to use simulation technology. On the other hand, smart gird is a general term, which generates various functions to face to modern power grid. In its core, smart grid makes uses of digital communication as well as the monitoring of control system and power flow of control to make the power grid with more elastic target and more effective cost.

Smart grid strengthens the connectivity of automation and coordination among suppliers, consumers and demand side management of grid features through the features of modern network, such as demand side management, implementing pricing, production as well as the activation and reading of automatic instrument. With the development of times, smart grid technology is improving gradually; in addition, the complexity of management grid is increasing too. Clients (electric utility, smart grid product and service supplier, owner/operator, stakeholder, supervisor and decision maker, evaluation, analysis and investigation, clients, standard development organization, academic circle, R\&D organization) pay increasing attention to the stability between environment and energy demand. It is very necessary for environment and resources to become measurement efficiency, reliability and service quality of smart grid to calculate its progress. Therefore, to provide current deployment of smart grid and make future plans in a better way, software is necessary. Up to now, a lot of models monitor most substantial equivalents, such as automation, integration, reliability and influence on economy. These models can evaluate the current situation of implemented smart grid, analyze future plan to improve current stage to the next level and bring improvement space to smart grid technology. 


\section{Available Software Model}

\section{Smart grid interoperability maturity model (SGIMM)}

SGIMM is automatic transmission system of monitoring measures and other fields developed by GridWise ${ }^{\circledR}$ Architecture Committee (GWAC). For allocation and demand side resources, it provides following functions, such as

- State/progress measurement statistics

- Gap analysis

- Efforts of priority, improve current situation

The main purpose of SGIMM is to set up an interoperability test model in operation performance and security of power system for promoting configuration and evolution in key fields. To realize this target, clear target and standard relation has been confirmed between different products and systems. It transfers these targets into a series of indexes. With the assistance of these indexes, it can determine the research progress and performance of product and system carefully. If some changes can be confirmed, it can define new standards and settings. Therefore, SGIMM can improve the quality of relevant specifications of smart grid technology.

\section{Smart Grid Investment Model (SGIM)}

SGIM is a financial model. Under their strategies, it is helpful to calculate the influence of different smart grids on investment. At the same time, it can also help us to calculate the cost of smart grid investment benefit and track the distribution situation. It provides following functions, such as

- Complete frame quarter, detailed financial cost and benefit calculation

- Predict the implementation plan of smart grid as well as the influence of clients and end users.

- Guide better smart grid investment analysis

- Suggestions for the smart grid strategies are in line with cost benefit.

SGIM is a program that confirms related technologies of smart grid based on the utility of smart grid and features of end users. This utility can be used to analyze the benefits of each technology in cost and benefits in the coming twenty years. This model can help smart grid to analyze current application status analysis plan through evaluating different investment choices and their influence on current utility and demand response plan.

\section{Smart grid maturity model (SGMM)}

SGMM is a progress management tool and it can be used to evaluate eight fields of smart grid in the implementation process, including (strategy, management and monitoring (SMR), organization structure (OS), grid operation (GO), work and asset management (WAM), technology (technology), client (client), value chain integration (VCI), social and environment (SE). It provides following functions, such as

- Set up one shared vision and guidelines for smart grid in the same process

- Communicate with stakeholders who use public platforms.

- Allocate different tasks based on proper order.

- Monitor and measure the progress in different fields.

- Develop new plan and revise the plan if needed.

The value of SGMM is measured based on compass and is produced based on the evaluation of investigation questionnaire. On the basis of this implication, we divide five different maturity levels (startup, providing, integration, optimization and entrepreneurship). This model is helpful for the career planning, priority task of smart grid transformation and measuring their progress at each stage.

\section{Smart grid concept model (SGCM)}

The concept model of smart grid provides a visualized sketch map to explain how to integrate different components of smart grid. It includes seven structural domains (client, market, service provider, operation, bulk generation, transmission and allocation). It provides following functions, such as: 
- Provide descriptive summary for the smart grid development.

- It provides context analysis of different standards and interoperability.

- Display interaction among different domains in distribution management system (DMS)

- It also integrates in network security, network management, data management and application integration.

\section{Applications in Smart Grid Monitoring Model}

The purpose of this research is to design a new network management, data management, application integration and security with more convenient work. This is helpful for us to realize advanced philosophy. For example, define different building standards, communication standards of performance features of smart grid, monitoring and load management technology, advanced component and operation concept as well as modeling and simulation of global information system.

Building standards include initial building frame, national grid system and its components. It includes quality standards of equipment, interface standard, background database and evaluation standard etc; all these should be standard and unified evaluation standards.

Communication standard includes proper standards between organizations, such as stakeholders and clients. Monitoring and load include management technology that monitors and controls demand side management load of industry/business/ housing.

The concept of advanced component and operation includes interconnection technology, progress of transformer substation as well as advanced system operation.

Modeling and simulation include emergency events and planning and operation support of event.

Global information system includes advanced and practical software system to realize smart grid. It can be used to map and analyze a lot of information produced by smart grid technology. Each component interacts with each other, as shown in figure 1.

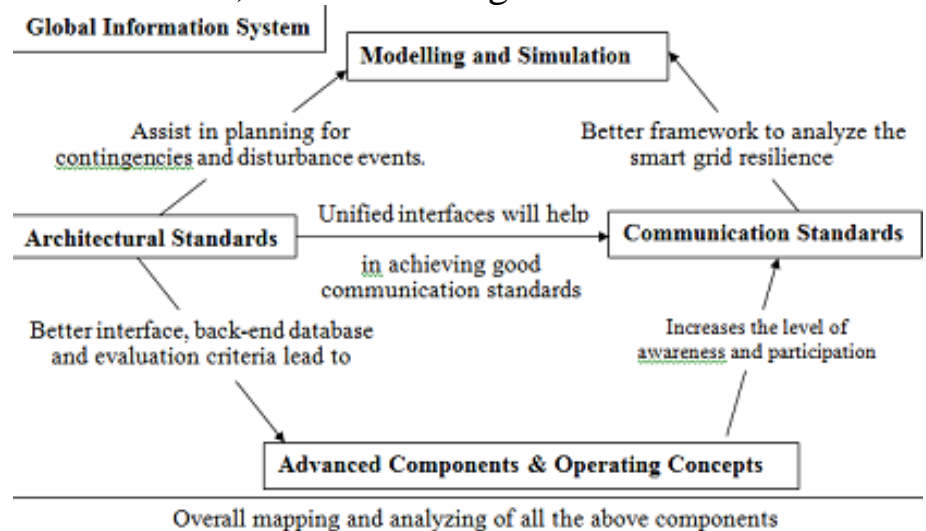

Fig.1. Interconnection between various components

\section{Conclusions}

Under one power system, model design will provide a complete frame for understanding deployment and capability of smart grid. This is helpful for the smart inspection and monitoring of smart grid. Main features of this model include:

- Opportunity of new product, service and market; new product and service open up new market and higher smart grid.

- Effectiveness of electric energy quality and power quality, stable voltage, elasticity and self-healing capability of interference and disaster

- Generation and storage options-integrate different and distributed power resources, such as solar energy, wind energy, geothermal energy and power grid.

- Consumer participation-consumer cognition and implementation program of smart grid, participation degree of consumers.

- Operation elasticity against disaster-realize the business elasticity and realization in disasters and smart grid. 
- Asset optimization and operation efficiency-realize real-time monitoring of equipment, asset optimization and realize operation efficiency.

- Technology-response, interceptions and interruptions in smart meter interference system become fast.

Finally, set up strategic target and implementation plan, which can support grid modernization and provide context.

\section{References}

[1] Pahlavan K, Krishnamurthy P and Geng Y, Localization challenges for the emergence of the smart workd. IEEE Access, 2015, 3(1), pp. 3058-3067

[2] Lv, Z., Tek, A., Da Silva, F., Empereur-Mot, C., Chavent, M., \& Baaden, M. (2013). Game on, science-how video game technology may help biologists tackle visualization challenges. PloS one, 8(3), e57990.

[3] Lv, Z., Halawani, A., Feng, S., Li, H., \& Réhman, S. U. (2014). Multimodal hand and foot gesture interaction for handheld devices. ACM Transactions on Multimedia Computing, Communications, and Applications (TOMM), 11(1s), 10.

[4] Weisen Pan, Shizhan Chen, Zhiyong Feng. Automatic Clustering of Social Tag using Community Detection. Applied Mathematics \& Information Sciences, 2013, 7(2): 675-681. 